\title{
Comparison of Bioactive Compounds and Quality Traits of Breast Meat from Korean Native Ducks and Commercial Ducks
}

\author{
Hyun Jung Lee, Dinesh D. Jayasena ${ }^{1,2}$, Sun Hyo Kim ${ }^{1}$, Hyun Joo Kim, Kang Nyung Heo², \\ Ji Eun Song, and Cheorun Jo* \\ Department of Agricultural Biotechnology, Center for Food and Bioconvergence, Research Institute of \\ Agriculture and Life Science, Seoul National University, Seoul 151-921, Korea \\ ${ }^{1}$ Department of Animal Science and Biotechnology, Chungnam National University, Daejeon 305-764, Korea \\ ${ }^{2}$ Department of Animal Science, Uva Wellassa University, Badulla 90000, Sri Lanka \\ ${ }^{3}$ Department of Poultry Science, National Institute of Animal Science, RDA, Cheonan 331-801, Korea
}

\begin{abstract}
The aim of this research was to compare the bioactive compound content and quality traits of breast meat from male and female Korean native ducks (KND) and commercial ducks (CD, Cherry Valley). Meat from three 6-wk old birds of each sex from KND and CD were evaluated for carcass and breast weights, $\mathrm{pH}$, color, cooking loss, shear force, and bioactive compound (creatine, carnosine, anserine, betaine, and L-carnitine) content. KND showed significantly higher carcass weights than $\mathrm{CD}$ whereas no such difference $(p>0.05)$ was found between male and female ducks. The breed and sex had no significant effects on the breast weight, $\mathrm{pH}$ value, and shear force. However, KND had significantly lower cooking loss values than did CD. Creatine, anserine, and L-carnitine contents were significantly higher in KND than in CD and were predominant in female ducks compared to males. The results of this study provide rare information regarding the amounts and the determinants of several bioactive compounds in duck meat, which can be useful for selection and breeding programs, and for popularizing indigenous duck meat.
\end{abstract}

Key words: meat quality traits, bioactive compounds, commercial duck, Korean native duck

\section{Introduction}

Meat and meat products are excellent sources for proteins, vitamins such as $\mathrm{B}_{12}$, and minerals (Jimenze-Colmenero et al., 2001), however, their risk related to cardiovascular diseases and colon and other cancers has also been reported (Kim et al., 2013; McAfee et al., 2010; Oostindjer et al., 2014), making consumers more concerned about meat consumption. As consumers understand more that food consumption is one of the important factors and can influence on human health (Goetzke, 2014; Lähteenmäki, 2013), consuming meat and meat products on our meal has been a controversial issue with their benefit and risk. Meanwhile, duck meat consumption in Korea has been increased approximately by 5-folds from 1997 to

\footnotetext{
*Corresponding author: Cheorun Jo, Department of Agricultural Biotechnology, Center for Food and Bioconvergence, Research Institute of Agriculture and Life Science, Seoul National University, Seoul, 151-921, Korea. Tel: +82-2-880-4804, Fax: +822-873-2211, E-mail: cheorun@snu.ac.kr
}

2012 (Korea Duck Association, 2013), which might be attributable to consumers' increasing concern about the consumption of healthier meat. Duck meat is considered to be healthier compared to other animal products as it contains higher unsaturated fatty acid, essential fatty acid, and protein contents, in addition to its ability to decrease LDL cholesterol and blood pressure (Heo et al., 2013; Kim et al., 2010a).

With the increase in duck meat consumption, considerable efforts have been made since 1990's to popularize duck meat as a healthier meat source to secure the competitiveness in world market. The present Korean native duck (KND) produced by National Institute of Animal Science (NIAS) is a crossbreed between mallard duck (Anas platyrhynchos) and meat-type duck (Kim et al., 2010a; Kim et al., 2010b). However, still $90 \%$ of the breeding ducks in Korea are the breeds from oversea such as Cherry Valley (England) and Grimaud (France) and only $10 \%$ of them are KND (Kim et al., 2012a). Hence, it is an urgent goal to preserve pure bloodlines and develop a commercial meat-type KND breed by utilizing indige- 
nous breeds such as Woorimatori ${ }^{\mathrm{TM}}$ [developing Korean indigenous breed by National Institute of Animal Science (NIAS), RDA, Korea] to meet the increasing demand for duck meat. In developing a meat-type KND breed, it is important to carry out more investigations on quality traits of duck meat. When the present KND is further improved, it may have a possibility to secure the competitiveness against other breeds or animal products.

Designing meat and meat products as functional foods has received more attention in the field of meat technology. Functional foods with beneficial impact on health (Goetzke et al., 2014) have become a worldwide trend and a craving for healthier food, and its market is continuously expanding based on increasing consumption and interest. Jimenez-Colmenero et al. (2001) and OlmedillaAlonso et al. (2013) agreed on an optimistic prediction for improving nutritional value and positive image of meat and meat products when they are developed as functional foods. In this regards, improving the bioactive compound content in meat and meat products can be an effective mean. Important bioactive compounds in meat include coenzyme $\mathrm{Q}_{10}$, taurine, conjugated linoleic acid, glutathione, lipolic acid, betaine, L-carnitine, creatine, carnosine, and anserine. They are abundant in mammalian skeletal muscles and have distinct biological functions in animal body, including working as a $\mathrm{pH}$ buffer, effective antioxidative and anti-aging agent, and an osmolyte. (de Zwart et al., 2003; Hipkiss, 1998; Schmid, 2009; Stenesh and Winnick, 1960).

During the development of KND, most of studies on duck meat were focused on productive aspect and basic quality traits (Heo et al., 2013; Kim et al., 2010a; Kim et al., 2010b; Kim et al., 2012a) rather than its functional properties. Research findings on the availability and amounts of bioactive compounds in duck meat, in particular KND meat, are scarce. Therefore, the aim of this research was to compare the bioactive compound content and other quality traits of the breast meat from KND and commercial ducks (CD). In addition, the effect of sex on the same parameters was tested.

\section{Materials and Methods}

\section{Sample preparation}

Frozen carcasses from three birds of each sex from different breeds, KND and CD (Cherry Valley), were purchased at $6 \mathrm{wk}$ of age from a local farm (Korea), and transported in frozen condition to a laboratory. Then, the carcasses were thawed at $4^{\circ} \mathrm{C}$ for $48 \mathrm{~h}$, deskinned, and deboned manually. After collecting breast meat from each carcass, they were minced separately using a mini chopper (CH180, Kenwood, China) for $30 \mathrm{sec}$ and used for the analysis. The carcass and breast weights (g) from each bird were also recorded.

\section{pH}

Each meat sample (1 g) was homogenized with $9 \mathrm{~mL}$ of distilled water using a homogenizer (T10 basic, Ika Works, Germany). The homogenates were centrifuged (Union 32R, Hanil Co., Ltd., Korea) at 3,000 rpm for 10 min and filtered (Whatman No. 4, Whatman PLC., UK). The $\mathrm{pH}$ value of each filtrate was measured using a $\mathrm{pH}$ meter (SevenGo, Mettler-Toledo International Inc. Switzerland) which was pre-calibrated using standard buffers ( $\mathrm{pH} 4.01,7.00$, and 9.21).

\section{Cooking loss}

Cooking loss was determined as the percentage weight loss of each meat sample after cooking. Meat samples (30 g) were vacuum packed (HFV-600L, Hankook Fujee Co., Ltd., Korea), heated in a water bath at $90^{\circ} \mathrm{C}$ for $15 \mathrm{~min}$ until a core temperature of $72^{\circ} \mathrm{C}$ was reached, and cooled in iced water. After recording the final weight, cooking loss was calculated as expressed below:

$$
\begin{aligned}
& \text { Cooking loss }(\%)= \\
& \frac{\text { Weight before cooking-Weight after cooking }}{\text { Weight before cooking }} \times 100
\end{aligned}
$$

\section{Shear force}

Cooked sample was cut into a $10 \times 10 \times 30 \mathrm{~mm}$ to measure shear force. The value was measured using a WarnerBratzler shear attachment on a texture analyzer (CT3 10K, Brookfield Engineering Laboratories., USA) with a maximum cell load, $10 \mathrm{~kg}$; target load, $10 \mathrm{~g}$; target value, 25 $\mathrm{mm}$; target speed $2.0 \mathrm{~mm} / \mathrm{sec}$. The samples were sheared perpendicularly to the direction of muscle fiber.

\section{Meat color}

The surface color measurements (CIE L*, a*, and $b^{*}$ values representing lightness, redness, and yellowness, respectively) of meat samples were measured using a colorimeter (CR-310, Minolta Co., Ltd., Japan) which was calibrated against a white reference tile (Minolta calibration plate, No. 14633072). Three observation readings were taken for each color measurement in order to minimize the possible errors and the average was used as one 
replicate.

\section{Creatine, anserine, and carnosine contents}

The creatine, anserine, and carnosine contents in the samples were determined as described by Mora et al. (2007). Minced meat sample (2.5 g) were homogenized (T10 basic, Ika Works) with $7.5 \mathrm{~mL}$ of $0.01 \mathrm{~N} \mathrm{HCl}$ at $13,500 \mathrm{rpm}$ for $1 \mathrm{~min}$. The homogenate was centrifuged at 3,000 rpm for $30 \mathrm{~min}$ (Union 32R, Hanil Co., Ltd., Korea), and $1 \mathrm{~mL}$ of the supernatant was transferred into a microtube and centrifuged at $10,000 \mathrm{rpm}$ for $10 \mathrm{~min}$ (HM-150IV, Hanil). After centrifugation, $0.5 \mathrm{~mL}$ of the supernatant was mixed with $1.5 \mathrm{~mL}$ of acetonitrile, and the mixture was centrifuged at $10,000 \mathrm{rpm}$ for $10 \mathrm{~min}$ (HM-150IV, Hanil), and the supernatant was filtered through a membrane filter $(0.2 \mu \mathrm{m})$ into a glass vial. The samples were injected into a high performance liquid chromatography (HPLC; Ultimate 3000, Thermo Fisher Scientific Inc., USA) system under the gradient condition of two mobile phases; mobile phase A was $0.65 \mathrm{mM}$ ammonium acetate in distilled water and acetonitrile (25:75 v/v, pH 5.5), and mobile phase B was $4.55 \mathrm{mM}$ ammonium acetate in distilled water and acetonitrile (70:30 v/v, pH 5.5). The analytical conditions for HPLC was set up as descri- bed: injection volume, $10 \mu \mathrm{L}$; column, Atlantis HILIC silica column, $4.6 \times 150 \mathrm{~mm}, 3 \mu \mathrm{m}$ (Waters Corp., USA); flow rate, $1.2 \mathrm{~mL} / \mathrm{min}$. A detector was used at $214 \mathrm{~nm}$ to determine the creatine, anserine, and carnosine contents. The contents of the compounds were calculated using a standard curve obtained from the standard (Sigma, USA) of each compound.

\section{Betaine and L-carnitine contents}

The betaine and L-carnitine contents were quantified following the modified method of Jayasena et al. (2014a). Five grams of each meat sample was added with $10 \mathrm{~mL}$ of acetonitrile-methanol (9:1) solution and homogenized (T10 basic, Ika Works) at 13,500 rpm for $30 \mathrm{~s}$. The homogenate was then centrifuged at 3,100 rpm for $5 \mathrm{~min}$ at $4^{\circ} \mathrm{C}$ (Union 32R, Hanil), and the supernatant was filtered into a $20-\mathrm{mL}$ volumetric flask through a funnel plugged with glass wool. The remaining filtrate was again mixed with $10 \mathrm{~mL}$ of acetonitrile-methanol solution and centrifuged (Union 32R, Hanil) under the same conditions. The resulting supernatant was collected in the same volumetric flask which was then filled with acetonitrile-methanol solution. Subsequently, $2 \mathrm{~mL}$ of this sample was transferred to a $15-\mathrm{mL}$ tube and then $810 \mathrm{mg}$ of $\mathrm{Na}_{2} \mathrm{HPO}_{4}$ and $90 \mathrm{mg}$ of $\mathrm{Ag}_{2} \mathrm{O}(9: 1 \mathrm{w} / \mathrm{w})$ were added. After vortex-mix- ing the solution, the sample tubes were dried by shaking without their caps in a shaking machine for $20 \mathrm{~min}$ and then centrifuged at 3,100 rpm for $5 \mathrm{~min}$ (Union 32R, Hanil, Korea). A $0.5-\mathrm{mL}$ aliquot of each supernatant sample was then mixed with $0.5 \mathrm{~mL}$ of derivative reagent ( $0.066 \mathrm{~g}$ of 18 -crown- 6 and $1.39 \mathrm{~g}$ of bromoacetophenone in $100 \mathrm{~mL}$ of acetonitrile) in a $15-\mathrm{mL}$ tube, voltexed, and heated in a water bath at $80^{\circ} \mathrm{C}$ for $60 \mathrm{~min}$. After cooling under running water, this mixture was filtered through a membrane filter $(0.2 \mu \mathrm{m})$ and analyzed in a HPLC system (Ultimate 3000, Thermo Fisher Scientific Inc., USA) to determine betaine and L-carnitine contents. Two mobile phases (A, $25 \mathrm{mM}$ ammonium acetate in which $\mathrm{pH}$ was adjusted to 3.0 using formic acid; B, acetonitrile) were used and the analytical condition for HPLC was set up as described: injection volume, $10 \mu \mathrm{L}$; column, Atlantis HILIC silica column, $4.6 \times 150 \mathrm{~mm}, 3 \mu \mathrm{m}$ (Waters Corp.); flow rate, $1.4 \mathrm{~mL} / \mathrm{min}$; detector was used at $254 \mathrm{~nm}$. Standard curves were obtained using the standard (Sigma) for each compound and then used for calculation of betaine and Lcarnitine contents.

\section{Statistical analysis}

Statistical analysis was performed using multifactorial analysis of variance (ANOVA) to estimate the effect of the breed and sex on quality traits and bioactive compound content of duck meat, and the significant differences between the mean values were identified with Tukey's multiple range test using SAS software at a confidence level of $p<0.05$ (SAS 9.3, SAS Institute Inc., USA).

\section{Results and Discussion}

\section{Carcass and breast weights}

Table 1 shows the effects of breed and sex on carcass and breast weights of ducks; KND had a significantly higher carcass weight than $\mathrm{CD}(p<0.05)$ whereas no such difference was found between male and female ducks (Table 1). As KND was known for their inferior growth rate compared with commercial breeds, NIAS made considerable efforts to improve the growth rate and developed KND in two main types; small-type and large-type (Heo et al., 2013; Kim et al., 2012a). Heo et al. (2013) evaluated the growth of large-type KND with increasing age and reported that KND reached a carcass weight of $1,801 \pm 50.6 \mathrm{~g}$ and a breast weight of $469.2 \pm 15.8 \mathrm{~g}$ at $6 \mathrm{wk}$ of their age which is similar to the results of the present study. 
Table 1. Carcass and breast weights (g) of Korean native ducks (KND) and commercial ducks (CD)

\begin{tabular}{|c|c|c|c|c|c|}
\hline \multirow{2}{*}{ Item } & \multicolumn{2}{|c|}{ Breed } & \multicolumn{2}{|c|}{ Sex } & \multirow{2}{*}{$\mathrm{SEM}^{1}$} \\
\hline & KND & $\mathrm{CD}$ & Male & Female & \\
\hline Carcass weight & $1898^{\mathrm{a}}$ & $1745^{\mathrm{b}}$ & 1866 & 1777 & 34.2 \\
\hline Breast weight & 352 & 325 & 330 & 348 & 11.5 \\
\hline Corr $^{2}$ & 0.32 & 0.11 & 0.58 & 0.81 & - \\
\hline
\end{tabular}

${ }^{1}$ Standard error of the means $(n=12)$.

${ }^{2}$ Corr $=$ correlation coefficient between carcass and breast weight at $p<0.05$.

${ }^{a, b}$ Means within the same row with different letters within the same effect differ significantly $(p<0.05)$.

Table 2. Meat quality traits of the breast meat from male and female Korean native ducks (KND) and commercial ducks (CD)

\begin{tabular}{cccccc}
\hline \hline Quality traits & \multicolumn{3}{c}{ Breed } & \multicolumn{3}{c}{ Sex } & \multirow{2}{*}{ SEM $^{1}$} \\
\cline { 2 - 5 } & KND & CD & Male & Female & 0.015 \\
pH & 5.93 & 5.90 & 5.91 & 5.92 & 0.365 \\
Cooking loss (\%) & $32.65^{\mathrm{b}}$ & $37.04^{\mathrm{a}}$ & $35.74^{\mathrm{a}}$ & $33.95^{\mathrm{b}}$ & 0.063 \\
Shear force (kg) & 2.59 & 2.72 & 2.60 & 2.71 & 0.492 \\
CIE L* $^{\text {CIE a* }}$ & $42.86^{\mathrm{b}}$ & $45.02^{\mathrm{a}}$ & $44.91^{\mathrm{a}}$ & $42.97^{\mathrm{b}}$ & 0.355 \\
CIE b* $^{*}$ & 21.26 & 20.43 & 20.86 & 20.84 & 0.244 \\
\hline
\end{tabular}

${ }^{1}$ Standard error of the means $(n=12)$.

${ }^{a, b}$ Means within the same row with different letters within the same effect differ significantly $(p<0.05)$.

\section{Meat quality traits}

The breed and sex of duck did not affect the $\mathrm{pH}$ value of breast meat in the present study (Table 2), and it is in agreement with the findings of Muhlisin et al. (2013). Furthermore, the $\mathrm{pH}$ value of breast meat observed in the present study was closer to that of Pekin ducks (Kim et al., 2012b). In contrast, several other researchers have reported much higher $\mathrm{pH}$ values for duck meat from A44 and A55 strains (6.0 and 6.4, respectively). However, the breed $\times$ sex interaction $(p=0.04)$ was found to be significant regarding the $\mathrm{pH}$ value of duck meat.

The $\mathrm{pH}$ value is one of the most important factors affecting meat quality traits because it has a direct effect on denaturation of meat proteins, influencing tenderness and water holding capacity and meat color (Hamoen et al., 2013). In our findings, $\mathrm{pH}$ value did not seem to have a positive effect on water holding capacity as a significant difference was found in cooking loss values between KND (32.65\%) and CD (37.04\%). Additionally, the sex and breed $\times$ sex interaction had significant effects on cooking loss values, in order of significance. Male ducks showed higher cooking loss values compared with female birds $(p<0.05$; Table 2). The shear force values of the duck breast meat were comparable between the breeds and sexes (Table 2). The shear force values of duck meat tested in this study was similar to that observed by Muhlisin et al. (2013) for imported CD (2.73). However, several previous studies have shown much higher shear force values for duck meat from Chungdongori (3.76; Ali et al.,
2008) and Pekin ducks (4.18; Kim et al., 2012b). The difference in shear force values among these studies might be attributable to the difference in breed and slaughter age (Muhlisin et al., 2013).

CIE color values of KND meat were reported as 36.9 $\pm 0.97,21.6 \pm 0.94$, and $8.78 \pm 0.64$ for $\mathrm{L}^{*}$-, a*-, and $\mathrm{b}^{*}$-values, respectively (Kim et al., 2010b). Our results showed a higher $\mathrm{L}^{*}$-value (42.97-45.02), a similar a*-value (20.43-21.26), and a lower $b^{*}$-value (6.62-7.47) compared to those of Kim et al. (2010b). However, Chae et al. (2005) reported meat color values of duck meat to be 39.80-46.51, 16.67-17.92, and 4.37-7.27 for $\mathrm{L}^{*}$-, $\mathrm{a}^{*}$-, and $\mathrm{b}^{*}$-values, respectively. Both breed and sex showed a significant effect on $L^{*}$-value of duck breast meat (Table 2). In this regards, $\mathrm{L}^{*}$-value was higher $(p<0.05)$ in $\mathrm{CD}$ and male duck meats compared to their counterparts. In addition, $b^{*}$-value was higher in the meat from male ducks compared to that from female ducks, but comparable between the breeds. Joo et al. (2013) explained the relationship between $\mathrm{L}^{*}$-value and water holding capacity of meat. With lowered water holding capacity, a higher loss of myoglobin and a greater reflection of light at the meat surface result in a higher $\mathrm{L}^{*}$-value. The $\mathrm{b}^{*}$-value can be related to $L^{*}$-value since intracellular fat content affects the increase in $b^{*}$-value and has a positive relationship with $L^{*}$-value (Sarries and Beriain, 2006). This explanation agrees with our findings regarding the significant difference observed in the $\mathrm{L}^{*}$-value between breeds and sexes. However, since there was no significant difference 
in the $\mathrm{a}^{*}$-value, which is known to be affected by the myoglobin content (Quevedo et al., 2013), the reflection of light at the meat surface and $\mathrm{b}^{*}$-value of meat must have contributed a greater proportion towards the higher $\mathrm{L}^{*}$-values observed in the current study.

\section{Bioactive compounds}

No scientific publications that compare the bioactive compounds of different breeds of ducks are available. Only a few studies have reported the presence of these endogenous compounds in meat from other species. Hence, these studies were considered in the following section to put our current findings into context. The contents of creatine, anserine, and L-carnitine in duck breast meat were affected by breed and sex (Table 3 ).

Creatine performs an important role in the energy metabolism of skeletal muscle (Wyss and KaddurahDaouk, 2000). Creatine is absorbed into body from meat and meat products after consumption, and it increases muscle power and performance (Schmid, 2009). A strong effect of the breed and sex on the creatine content of duck breast meat was observed in the present study; KND and female birds showed significantly higher creatine contents than their counterparts (Table 3). A previous study showed similar findings regarding the creatine content of Korean native chickens (KNC); female $\mathrm{KNC}$ had significantly higher creatine content than male KNC (Jayasena et al., 2015). In contrast, Jung et al. (2013) revealed that sex did not influence the creatine content of KNC meat, but influenced the line of $\mathrm{KNC}(p<0.0001)$.

Carnosine and anserine are dipeptides composed of $\beta$ alanine and L-histidine and anserine is derived from carnosine (Hipkiss, 1998; Stenesh and Winnick, 1960). These compounds have $\mathrm{pH}$ buffering, antioxidative, and antiaging roles. In addition, meat and meat products are the main dietary source of carnosine and anserine for humans (Schmid, 2009). Comparable carnosine contents were found $(p>0.05)$ between the two breeds and between male and female birds in the current study (Table 3). In contrast, Jayasena et al. (2014b) reported that the carnosine content of $\mathrm{KNC}$ meat was significantly higher than that of commercial broiler (CB) meat $(p<0.05)$. Marlin et al. (1989) and Mateescu et al. (2012) demonstrated that carnosine content was not related to sex of the animal. However, Jung et al. (2013) demonstrated a sex effect on the carnosine content of KNC meat; female birds had significantly higher carnosine contents than did male birds.

The present study showed that the breed, sex, and breed $x$ sex interaction significantly affected the anserine content of duck breast meat, in order of significance (data not shown). In this regards, KND and female ducks showed higher anserine contents in the breast meat (49.18 and $46.64 \mathrm{mg} / 100 \mathrm{~g}$, respectively) compared with $\mathrm{CD}$ and male ducks (36.72 and $39.27 \mathrm{mg} / 100 \mathrm{~g}$, respectively). This is in well agreement with the results of Jayasena et al. (2014b) who observed that the anserine content of KNC meat was significantly higher than that of $\mathrm{CB}$ meat $(p<$ 0.05). However, Jung et al. (2013) found that the anserine content of KNC meat was also not affected by the bird sex. Peñafiel et al. (2004) explained that carnosine content has a positive correlation with testosterone. In addition, duck meat contained more anserine than carnosine, irrespective of the breed and sex, which is in agreement with previous findings that anserine was the principal histidine dipeptide in poultry meat (Abe and Okuma, 1995; Jayasena et al., 2014a). The anserine contents of meat are governed by muscle type, species, breed, gender, age, and breeding (Abe and Okuma, 1995; Chan and Decker, 1994; Jayasena et al., 2014a). Hence, the higher anserine content of KND meat compared to that of CD meat may be attributed to breed effect.

Betaine acts as an osmolyte to preserve osmotic equilibrium and also interacts with fat metabolism resulting in fat reduction (de Zwart et al., 2003; Fernández et al., 1998). According to the findings of the current study, the betaine content of duck breast meat was similar $(p>0.05)$

Table 3. Bioactive compound content of the breast meat ( $\mathrm{mg} / 100 \mathrm{~g})$ from male and female Korean native ducks (KND) and commercial ducks $($ CD)

\begin{tabular}{|c|c|c|c|c|c|}
\hline \multirow{2}{*}{ Compound } & \multicolumn{2}{|c|}{ Breed } & \multicolumn{2}{|c|}{ Sex } & \multirow{2}{*}{ SEM $^{1}$} \\
\hline & KND & $\mathrm{CD}$ & Male & Female & \\
\hline Creatine & $128.99^{\mathrm{a}}$ & $121.85^{b}$ & $119.59^{b}$ & $131.25^{\mathrm{a}}$ & 1.275 \\
\hline Carnosine & 14.36 & 16.49 & 15.90 & 14.95 & 1.114 \\
\hline Anserine & $49.18^{\mathrm{a}}$ & $36.72^{\mathrm{b}}$ & $39.27^{b}$ & $46.64^{\mathrm{a}}$ & 2.051 \\
\hline Betaine & 4.06 & 4.04 & 3.90 & 4.21 & 0.201 \\
\hline L-carnitine & $8.33^{\mathrm{a}}$ & $6.76^{\mathrm{b}}$ & $6.83^{\mathrm{b}}$ & $8.26^{\mathrm{a}}$ & 0.272 \\
\hline
\end{tabular}

${ }^{1}$ Standard error of the means $(n=12)$.

${ }^{a, b}$ Means within the same row with different letters within the same effect differ significantly $(p<0.05)$. 
between KND (4.06 mg/100 g) and CD (4.04 mg/100 g) and between male ducks $(3.90 \mathrm{mg} / 100 \mathrm{~g})$ and females (4.21 mg/100 g; Table 3). KNC had a betaine content of 3.55-5.05 mg/100 g (Jayasena et al., 2014a). In contrast, Jayasena et al. (2014b) revealed that the betaine content of $\mathrm{KNC}$ meat was significantly lower than that of $\mathrm{CB}$ meat $(p<0.05)$. L-carnitine combines with long chained fatty acids forming L-carnitine esters and fat combustion takes place though $\beta$-oxidation in mitochondria (Schmid, 2009). According to our results, L-carnitine content of duck breast meat was influenced both by the breed and sex, in order of significance (data not shown). The L-carnitine contents of KND and CD were $8.33 \mathrm{mg} / 100 \mathrm{~g}$ and $6.76 \mathrm{mg} / 100 \mathrm{~g}$ whereas those of male and female ducks were $6.83 \mathrm{mg} / 100 \mathrm{~g}$ and $8.26 \mathrm{mg} / 100 \mathrm{~g}$, respectively (Table 3). Similarly, L-carnitine content of KNC meat was significantly higher than that of $\mathrm{CB}$ meat (Jayasena et al., 2014b).

In general, $\mathrm{KNC}$ had higher bioactive compound contents (Jayasena et al., 2014a; Jung et al., 2013), except betaine and L-carnitine, compared to KND. This confirms that bioactive compound content of meat is dependent on the animal species. Table 4 shows that the carnosine and anserine contents were positively related ( 0.04 and 0.81 , respectively) to the breast weight of KND and negatively related $(-0.40$ and -0.18 , respectively) to that of CD.

In addition, the betaine, L-carnitine, and creatine contents were related to the breast weight of KND compared with that of CD (Table 4).

\section{Conclusion}

KND had a higher carcass weight and a lower cooking loss value compared to $\mathrm{CD}$. Furthermore, the KND contained higher levels of creatine, anserine, and L-carnitine than CD. The content of same compounds was higher in female ducks than in males. The findings of the present

Table 4. Pearson's correlation coefficient of bioactive compounds and breast weight from male and female Korean native ducks (KND) and commercial ducks (CD)

\begin{tabular}{ccccc}
\hline \hline \multirow{2}{*}{ Compound } & \multicolumn{2}{c}{ Breed } & \multicolumn{2}{c}{ Sex } \\
\cline { 2 - 5 } & KND & CD & Male & Female \\
\hline Creatine & 0.71 & 0.38 & 0.87 & 0.63 \\
Carnosine & 0.04 & -0.40 & -0.37 & 0.20 \\
Anserine & 0.81 & -0.18 & 0.62 & 0.63 \\
Betaine & 0.59 & 0.56 & 0.37 & 0.66 \\
L-carnitine & 0.68 & 0.12 & 0.38 & 0.70 \\
\hline
\end{tabular}

study are useful to disseminate the information regarding the availability and amounts of bioactive compounds in duck meat, particularly in KND meat. However, further studies on endogenous compounds in duck meat from genetically-proven KND such as Woorimatori ${ }^{\mathrm{TM}}$ and CD should be investigated.

\section{Acknowledgements}

This research was carried out with the support of "Cooperative Research Program for Agriculture Science \& Technology Development (Project No. PJ01011402)", Rural Development Administration, Republic of Korea and Institute of Green Bio Science and Technology, Seoul National University, Republic of Korea.

\section{References}

1. Abe, H. and Okuma, E. (1995) Discrimination of meat species in processed meat products based on the ratio of histidine dipeptides. J. Jpn. Soc. Food Sci. 42, 827-834.

2. Ali, M. S., Yang, M. S., Jeong, J. Y., Moon, S. H., Hwang, Y. H., Park, G. B. and Joo, S. T. (2008) Effect of chilling temperature of carcass on breast meat quality of duck. Poultry Sci. 87, 1860-1867.

3. Chae, H. S., Yoo, Y. M., Ahn, C. N., Kim, D. H., Ham, J. S., Jeong, S. K., Lee, J. M., and Choi, Y. I. (2005) Effect of rearing period on yield rate, physical properties and fatty acid composition of duck meats. Korean J. Food. Sci. An. 25, 304309.

4. Chan, K. M. and Decker, E. A. (1994) Endogenous skeletal muscle antioxidants. Crit. Rev. Food Sci. Nutr. 34, 403-426.

5. de Zwart, F. J., Slow, S., Payne, R. J., Lever, M., George, P. M., Gerrard, J. A., and Chambers, S. T. (2003) Glycine betaine and glycine betaine analogues in common foods. Food Chem. 83, 197-204.

6. Fernández, C., Gallego, L., and Lopez-Bote, C. J. (1998) Effect of betaine on fat content in growing lambs. Anim. Feed Sci. Technol. 73, 329-338.

7. Goetzke, B., Nitzko, S., and Spiller, A. (2014) Consumption of organic and functional food. A matter of well-being and health? Appetite 77, 96-105.

8. Hamoen, J. R., Vollebregt, H. M., and van der Sman, R.G.M. (2013) Prediction of the time evolution of pH in meat. Food Chem. 141, 2363-2372.

9. Heo, K. N., Kim, H. K., Kim, C. D., Kim, S. H., Lee, M. J., Choo, H. J., Son, B. R., Choi, H. C., Lee, S. B., and Hong, E. C. (2013) Evaluation of Korean native ducks on production efficiency factor, carcass yield, partial meat ratio and meat quality with weeks. Korean J. Poult. Sci. 40, 121-127.

10. Hipkiss, A. R. (1998) Carnosine, a protective, anti-ageing peptide? Int. J. Biochem. Cell Biol. 30, 863-868.

11. Jayasena, D. D., Jung, S., Bae, Y. S., Kim, S. H., Lee, S. K., Lee, J. H., and Jo, C. (2014a). Changes in endogenous bioac- 
tive compounds of Korean native chicken meat at different ages and during cooking. Poultry Sci. 93, 1842-1849.

12. Jayasena, D. D., Jung, S., Bae, Y. S., Park, H. B., Lee, J. H. and Jo, C. (2014b). Comparison of the amounts of endogenous bioactive compounds in raw and cooked meats from broilers and indigenous chickens. J. Food Comp. Anal. 37, 20-24.

13. Jayasena, D. D., Jung, S., Kim, S. H., Kim, H. J., Alahakoon, A. U., Lee J. H., and Jo, C. (2015) Endogenous functional compounds in Korean native chicken meat are dependent on sex, thermal processing and meat cut. J. Sci. Food Agric. 95, 771-775.

14. Jiménez-Colmenero, F., Carballo, J., and Cofrades S. (2001) Healthier meat and meat products: their role as functional foods. Meat Sci. 59, 5-13.

15. Joo, S. T., Kim, G. D., Hwang, Y. H., and Ryu, Y. C. (2013) Control of fresh meat quality through manipulation of muscle fiber characteristics. Meat Sci. 95, 828-836.

16. Jung, S, Bae, Y. S., Kim, H. J., Jayasena, D. D., Lee, J. H., Park, H. B., Heo, K. N., and Jo, C. (2013) Carnosine, anserine, creatine, and inosine 5'-monophosphate contents in breast and thigh meats from 5 lines of Korean native chicken. Poultry Sci. 92, 3275-3282.

17. Kim, E., Coelho, D., and Blachier, F. (2013) Review of the association between meat consumption and risk of colorectal cancer. Nutr. Res. 33, 983-994.

18. Kim, H. K., Hong, E. C., Kang, B. S., Park, M. N., Chae, H. S., Bang, H. T., Seo, B. Y., Choo, H. J., Na, S. H., Seo, O. S., and Hwangbo, J. (2010a) Effect of crossbred Korean native ducks on the retail cut yield, meat quality, and sensory evaluation of duck meats. Korean J. Poult. Sci. 37, 423-431.

19. Kim, H. K., Hong, E. C., Kang, B. S., Park, M. N., Seo, B. Y., Choo, H. J., Na, S. H., Bang, H. T., Seo, O. S., and Hwangbo, J. (2010b) Effect of crossbreeding of Korean native duck and broiler ducks on performance and carcass yield. Korean $J$. Poult. Sci. 37, 229-235.

20. Kim, H. K., Kang, B. S., Hwangbo, J., Kim, C. D., Heo, K. N., Choo, H. J., Park, D. S., Suh, O. S., and Hong, E. C. (2012a) The study on growth performance and carcass yield of meat-type Korean native ducks. Korean J. Poult. Sci. 39, 45-52.

21. Kim, H. W., Lee, S. H., Choi, J. H., Choi, Y. S., Kim, H. Y., Hwang, K. E., Park, J. H., Song, D. H., and Kim, C. J. (2012b) Effect of rigor state, thawing temperature, and processing on the physicochemical properties of frozen duck breast muscle. Poultry Sci. 91, 2662-2667.

22. Korea Duck Association (2013) General statistics: Per capita duck meat consumption. Available from: http://www.koreaduck.org/. Accessed June 22, 2014.

23. Lähteenmäki, L. (2013) Claiming health in food products. Food Qual. Pref. 27, 196-201.

24. Marlin, D. J., Harris, R. C., Gash, S. P., and Snow, D. H. (1989) Carnosine content of the middle gluteal muscle in thorough- bred horses with relation to age, sex and training. Comp. Biochem. Physiol. A. 93, 629-632.

25. Mateescu, R. G., Garmyn, A. J., O’Neil, M. A., Tait, R. G., Abuzaid, A., Mayes, M. S., Garrick, D. J., Van Eenennaam, A. L., VanOverbeke, D. L., Hilton, G. G., Beitz, D. C., and Reecy, J. M. (2012) Genetic parameters for carnitine, creatine, creatinine, carnosine, and anserine concentration in longissimus muscle and their association with palatability traits in Angus cattle. J. Anim. Sci. 90, 4248-4255.

26. McAfee, A. J., McSorley, E. M., Cuskelly, G. J., Moss, B. W., Wallace, J. M. W., Bonham, M. P., and Fearon, A. M. (2010) Red meat consumption: An overview of the risks and benefits. Meat Sci. 84, 1-13.

27. Mora, L., Sentandreu, M. A., and Toldrá, F. (2007) Hydrophilic chromatographic determination of carnosine, anserine, balenine, creatine, and creatinine. J. Agr. Food Chem. 55, 46644669.

28. Muhlisin, Kim, D. S., Song, Y. R., Kim, H. R., Kwon, H. J., An, B. K., Kang, C. W., Kim, H. K., and Lee, S. K. (2013) Comparison of meat characteristics between Korean native duck and imported commercial duck raised under identical rearing and feeding condition. Korean J. Food Sci. An. 33, 89-95.

29. Olmedilla-Alonso, B., Jiménez-Colmenero, F., and SánchezMuniz, F. J. (2013) Development and assessment of healthy properties of meat and meat products designed as functional foods. Meat Sci. 95, 919-930.

30. Oostindjer, M., Alexander, J., Amdam, G. V., Andersen, G., Bryan, N. S., Chen, D., Corpet, D. E., Smet, S. D., Dragsted, L., O., Haug, A., Karlsson, A. H., Kleter, G., de Kok, T., Kulseng, B., Milkowski, A. L., Martin, R. J., Pajari, A. Ma., Paulsen, J. E., Pickova, J., Rudi, K., Sødring, M., Weed, D. L., and Egelandsdal, B. (2014) The role of red and processed meat in colorectal cancer development: a perspective. Meat Sci. 97, 583-596.

31. Peñafiel, R., Ruzafa, C., Monserrat, F., and Cremades, A. (2004) Gender-related differences in carnosine, anserine and lysine content of murine skeletal muscle. Amino Acids 26, 53-58.

32. Quevedo, R., Valencia, E., Cuevas, G., Ronceros, B., Pedreschi, F., and Bastías J. M. (2013) Color changes in the surface of fresh cut meat: A fractal kinetic application. Food Res. Int. 54, 1430-1436.

33. Sarriés, M. V., and Beriain, M. J. (2006) Colour and texture characteristics in meat of male and female foals. Meat Sci. 74, 738-745.

34. Schmid, A. (2009) Bioactive substances in meat and meat products. Fleischwirtschaft 89, 83-90.

35. Stenesh, J. J. and Winnick, T. (1960) Carnosine-anserine synthetase of muscle. Biochem. J. 77, 575-581.

36. Wyss, M. and Kaddurah-Daouk, R. (2000) Creatine and creatinine metabolism. Physiol. Rev. 80, 1107-1213.

(Received 2014.7.29/Revised 2014.12.26/Accepted 2014.12.29) 